\title{
SEEKING A NEW ARCHITECTURAL PARADIGM
}

\author{
ANA NIKEZIĆ \& NATAŠA JANKOVIĆ \\ University in Belgrade, Faculty of Architecture, Serbia.
}

\begin{abstract}
This article presents the design methods and results of research conducted by Master's degree students on situating an architectural intervention in the protected natural landscape of Park Forest Košutnjak. The aim was an attempt to put this important, albeit widely neglected, park forest back on the cultural map of Belgrade. This meant that a high level of urbanity could be achieved by way of reorganising its structure, increasing its vitality, attractiveness and accessibility, while preserving its value as heritage landscape.

Architecture does not regard nature simply as a physical backdrop for the built structure. The elements and rhythms of complex natural phenomena, through topography, climate and vegetation, become an inspiring part of the architectural discourse. Thus, nature and architecture are allowed to intersect and intertwine, affecting the process of urban living and creating a new cultural landscape.

This article suggests that the treatment of protected landscape requires a new architectural paradigm, in which nature and architecture would form a unique place-based system. This approach would contribute not only to resolving the problem of how to revitalise a park forest but also to raising awareness of the adaptive quality that such a place possesses in the context of environmental change.

Keywords: Architecture, design project, landscape, nature, students.
\end{abstract}

\section{THE BACKGROUND}

At the beginning of the 21st century, when most of the world's population lives in cities and when architecture is mainly associated with the built structure, it seems as if man has forgotten how to enjoy nature. Today's cities are in a sensitive phase of development, in which economic parameters have permeated culture, significantly affecting the balance between socio-economic demands and cultural values of a place. In the circumstances when the design is produced in the disappearing natural landscape within urban environment, seeking for a new architectural paradigm represents a particular challenge.

Košutnjak Park Forest was declared a cultural heritage in 1986. In the midst of a dense urban setting, it spreads over an area of 330 ha on the slopes of the city centre, at an altitude of $250 \mathrm{~m}$ (Fig. 1). It is both a city resort and a habitat for diverse wildlife species. In historical, social, political and economic sense, its importance and status have been changing with the city since its establishment.

The important role of Košutnjak in the life of the city dates back to the Principality of Serbia (1817-1882). At that time, its grounds were used for hunting and as a leisure zone, in which the Prince built his second home with a park, a church and neighbourhood facilities. The most intriguing remains from this period are the Hajduk fountain (notorious as the place where Prince Mihailo Obrenović was assassinated in 1868), the King's Railway Station, Belgrade's first tramline and the Hippodrome. After the Second World War, Košutnjak was dedicated to the Pioneers (a youth organisation) as a meeting place, with a children's park and a railway built especially for them. By the second half of the 20th century, after rapid urbanisation and expansive growth outside Belgrade's central area, Košutnjak had become a part of dense urban environment.

Nowadays, Košutnjak is a space lost in the narrow margin between history and transition to the future: vacillating between heritage and decay, it is neither pure landscape nor a cultural hotspot. It is a public space without an explicit urban character, excluded from the mainstream of contemporary cultural life of the city. Admittedly, it hosts a few isolated and rather minor events, such as a crosscountry race, a blues festival or a forest festival, none of which lends a recognisable identity to the

(C) 2014 WIT Press, www.witpress.com

ISSN: 1755-7437 (paper format), ISSN: 1755-7445 (online), http://journals.witpress.com

DOI: 10.2495/DNE-V9-N1-47-55 


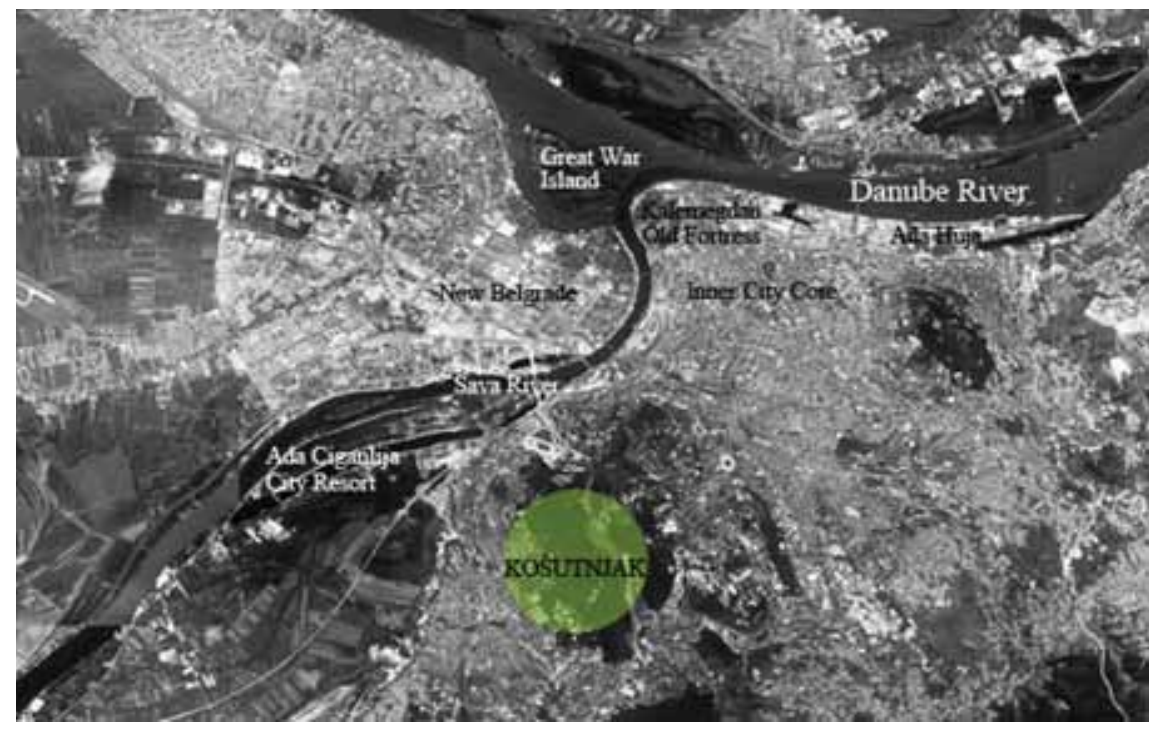

Figure 1: Situating Košutnjak Park Forest in Belgrade.

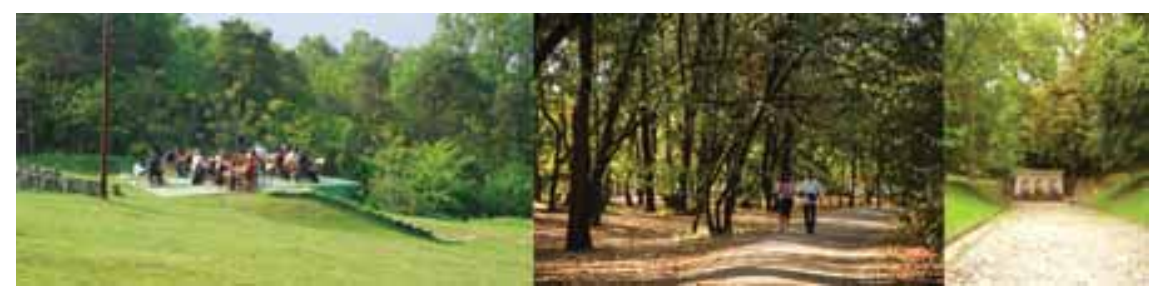

Figure 2: Košutnjak Park Forest in Belgrade and some of its characteristics.

space (Fig. 2). However, with its cultural, historical and morphological characteristics, Košutnjak can contribute to the improved environmental and cultural quality of the city of Belgrade.

\section{THE WORKING PROCESS}

As a part of the first-year Master's program at the Faculty of Architecture, University of Belgrade, 15 students of Architectural Design Studio had a task to examine the position and scope of architectural intervention aimed at potential rehabilitation of the protected landscape of Košutnjak Park Forest in Belgrade (e.g. [1]).

There was a twofold reason for choosing the protected urban park forest as a research polygon:

1. Insufficient awareness of the importance of urban forests and of the relationship between natural qualities and protected cultural-historical values of the site.

2. The distinct, even antithetical, relationship between architecture and landscape, in which architectural intervention requires acts of translation in order to offer a new, creative perspective for cultural landscape.

The students were expected to discover limitations and find new possibilities in networking nature and architecture. They reconsidered the connection between the city and the landscape through a 
limited and inconspicuous architectural intervention, which would restructure nature without disturbance, and include all its attributes (rhythms, diurnal and seasonal changes, morphological features, the ecosystem, etc.) as positive stimulants. The result would be architecture created to emphasise and promote nature. The task was to determine the relationship between an architectural intervention, freed from content and program, and nature, in all its states and transitions.

Such a provocative and dynamic challenge produced a set of research topics, among which the most imposing were:

- Positioning Košutnjak in contemporary urbanity (through rhythm, content, network, etc.);

- Analysing the values, potentials, obstacles and emphases of Košutnjak.

- Discovering events and activities that Košutnjak could offer and complement.

- Investigating how the forest could become vibrant and attractive in an urban setting.

- Questioning the interpretative potential of architecture through small-scale design.

- Opposing small-scale architecture to large-scale nature.

- Networking a large forest area with the city through small architectural interventions.

The working process was developed in three stages: research, conceptualisation and design.

\subsection{Research}

The research was conducted with respect to two aspects: analysing the spatial and programmatic potential of the Košutnjak Park Forest and studying the theoretical basis for establishing the relationship between architecture and nature (Fig. 3). In order to adopt the final architectural approach, these two aspects were examined simultaneously as to emphasise the critical notions of a particular context.

The students conducted individual place-based research of the spatial polygon and discussed theoretical approaches. They were prompted to think beyond the visual and to explore the domain of tactile, auditory, visual, olfactory and similar sensations related to the landscape of Košutnjak. They were also encouraged to appreciate the echoes and memories of its former uses, the remains of which were more or less evident in the forest.

\begin{tabular}{|c|c|}
\hline Characteristics of the forest: & Theoretical basis: \\
\hline $\begin{array}{l}\text { Permanent material features: } \\
\text { morphology, infrastructure, boundaries, } \\
\text { physical structures, places of heritage, } \\
\text { vistas, etc. }\end{array}$ & $\begin{array}{l}\text { Towards designed nature: references [1], [2] } \\
\text { - definition of landscape, } \\
\text { - relationship between nature and architecture, } \\
\text { - topographically tangible and spiritually } \\
\text { intangible. }\end{array}$ \\
\hline \multirow[t]{2}{*}{$\begin{array}{l}\text { Changeable material features: } \\
\text { seasonal cycles, } \\
\text { vegetation, memory, colours, light and shade, } \\
\text { sound and resonance, winds, etc. }\end{array}$} & $\begin{array}{l}\text { Towards sustainable architecture: references } \\
\text { [3], [4] } \\
\text { - sustainability as a better life quality for society, } \\
\text { - "smart" and "vital" architecture, } \\
\text { - dialogue between man's experience and nature. }\end{array}$ \\
\hline & $\begin{array}{l}\text { Towards comfortable place: references [5], }[6] \\
\text { - intimate understanding of the place, } \\
\text { - careful management of local climate conditions, } \\
\text { - multi-sensory experience [7]. }\end{array}$ \\
\hline
\end{tabular}

Figure 3: Research methodology. 


\begin{tabular}{|c|c|c|}
\hline $\begin{array}{l}\text { Model of the event } \\
\text { - character of the event, } \\
\text { - relationship between man } \\
\text { and nature, } \\
\text { - aspiration towards a sense } \\
\text { of place. }\end{array}$ & $\begin{array}{l}\text { Model of the spatial experience } \\
\text { - structural character of the place, } \\
\text { - framing the extent of the } \\
\text { intervention, } \\
\text { - desired character of created } \\
\text { structure. }\end{array}$ & $\begin{array}{l}\text { Model of the relationship } \\
\text { between architecture and nature } \\
\text { - material and sensual character } \\
\text { - structure, texture, articulation, } \\
\text { - concept vs. content vs. context. }\end{array}$ \\
\hline
\end{tabular}

Figure 4: Concept methodology.

\subsection{Conceptualisation}

After the comprehensive research of Košutnjak, the process of exact intervention in the site was developed through conceptual models. This phase implied a series of working models through which the students examined various logics defined through the interaction between architecture and nature. The students were then asked to think of the future character of the place, and using the physical model as a tool for presenting a previously perceived sensation or a vague icon, to materialise their aspiration towards the sense of the place. Three different stages were proposed (Fig. 4).

The first and the second models were used to set a clear purpose and character of the place and architecture, respectively. At this stage, the models were discussed in terms of features relative to spatial dualities and articulation (transparency, fragility, fullness or emptiness, etc.), with the purpose of giving a physical shape to the previously set goals. The students learned that the appearance of a structure might not be as important as its operability and its contribution to the relationship between man and context.

The result was a rationalised and materialised sensation, a distinct characteristic in which architecture and nature had equal values; they seemed to have united. Although architecture was vague, space impressions were clear in terms of colour, materiality, sound or contrast of light and shade. In that sense, the students were challenged with the problem of how to use architecture as a meaningful tool.

\subsection{Design}

As the final objective of the research, this stage yielded the expected design product - naturalised architecture as a multi-sensory experience. By the mutual superimposition of the landscape and the city, this concept was intended to support both the natural elements (earth, water, sky and vegetation, materialised through light and shadow, sound, softness and hardness) and the artificial elements (volumes defined through vertical and horizontal planes, borderlines and openings, articulated through rhythm, hierarchy and contrast). Architectural intervention fostered qualities of nature, regarding architecture as an infrastructure that allowed nature to take its place on the cultural map of Belgrade.

The previously defined topics, such as networking landscape with the city, connecting large and small scales, or promoting the environment over architecture, were the right choice for the beginning of the Master's program.

\section{THE RESULTS}

The students' design projects are the concrete results of the research that showed the potential of Košutnjak Park Forest as a valuable resource for Belgrade. Classified according to size, the featured 
projects represent a conscious shift towards a designing process that speaks directly of the values of the place. The versatility of the program testifies that a 'seizure of nature' is not necessarily wrong; on the contrary, it may contribute to the vitality of the chosen site as well as to the quality of contemporary everyday life (Figs 5 and 6).

\section{R1_Katarina Ristić: Watching the Stars}

Watching the Stars promotes an activity possible only in places far away from the unfailing city traffic. The goal is to provide as many different experiences of the same phenomenon. The elements of nature the project benefits from are the hill, the rock, and the lake. An additional set of architectural elements effectively outline the elements of nature, making them useful and comprehensive; the door complements the hill, the rock complements the stairs, and the lake complements the path. Architecture is hidden under nature's materiality, becoming a piece of clear ground encircled by the forest. In that sense, architecture becomes invisible and allows the main content to become its most important attribute: gazing at the stars.

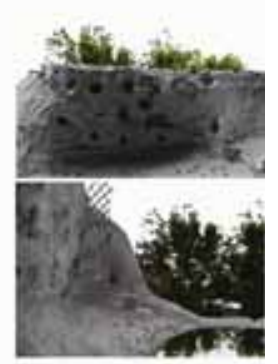

\section{R2_Miloš Milovanović: Temple of Nature}

The Temple of Nature transposes the pereeived analogy between Košutnjak and traditional monastery complex through the design of the botanical garden. Botanical garden keeps what is "sacred" for this area; the wildlife, on one side and resting activity, on the other. It adapts some monastery life rituals, such as drying of herbs, fishing from the lake, maintenance of plants, and the possibility of finding intimate spaces for social gatherings and independent contemplation. The lake is at the center of this botanical garden. The stairs are designed for observation and along with the rock on which it stands forms a spiral staircase.

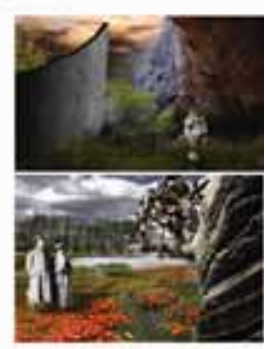

\section{R3_Milena Vukićević: The Break}

The Break articulates and accents the particular spirit of the forest. Carefully chosen places are coded as intermissions or breaks while the experiences and activities happening within them represent their counterpart, an anti-break. The essence is in ereating an abstract representation of the landscape. Therefore, three "rooms" were formed: the Earth Room, the Plant Room, and the Sky Room, as three separate layers of Košutnjak. Emphasizing nature with minimal use of architectural elements, the proposed design successfully creates a leisure space, a "piece" of nature included in the urban life as its resting place: the pause.

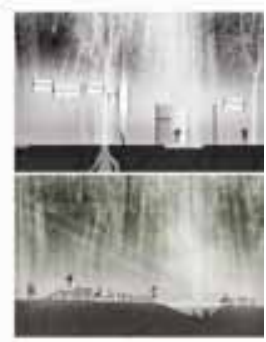

R4_Tatjana Vorinski: Being on the Verge, Being Inside, Wondering Through

Dynamic and comprehensive involvement of man and nature is the main premise of the design. Through exploring the existing pedestrian paths and their alternations, dead ends and numerous windings, three different Košutnjak situations are imagined: being inside, being on the verge, and wondering through, as to highlight particular human sensations through basic architectural elements and their articulation in natural environment. The proposed design opens new paths through the forest in a way that we might otherwise avoid, by levitating above, inserting between, and indenting through.

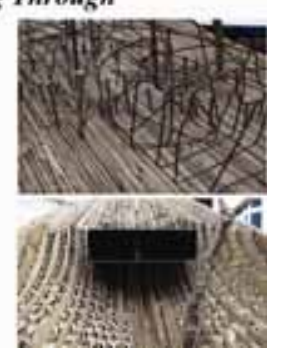

Figure 5: Examples of students' design projects. 


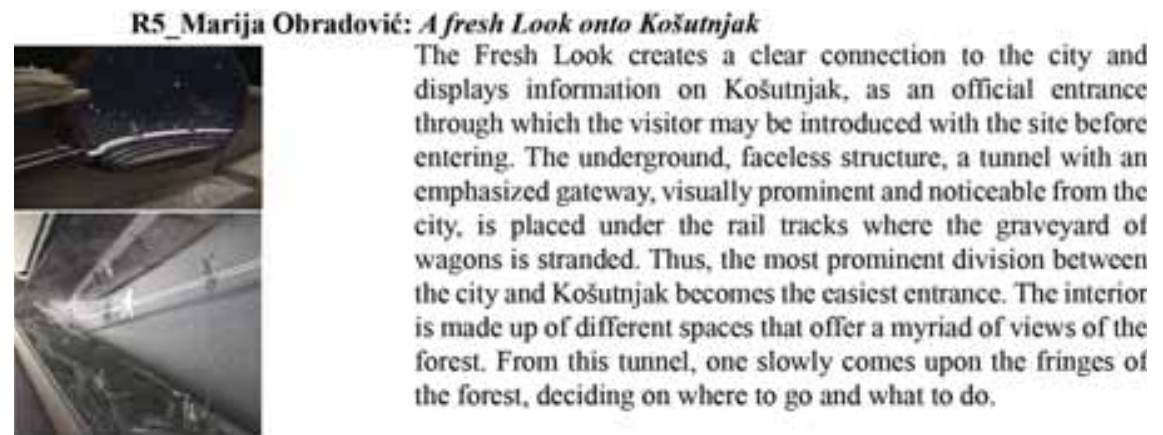

R6_Tamara Kuljanin: Urban Forest

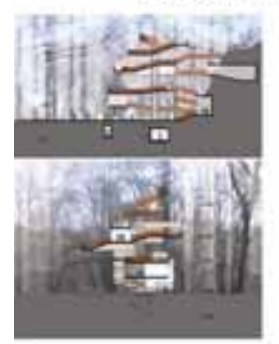

Urban Forest enables a set of urban leisure activities through a vertical structure. The design introduces a "pathway" which gathers spaces vertically in five different levels: underground, on the ground, beneath, above, and in the level of the tree crown. By assigning them an urban activity, it engages the forest in contemporary urban lifestyle, creating a narrow underground corridor (subculture), a strolling platform on the ground level (window-shopping), an amphitheatre beneath the crown (anticipating high culture), a coffee bar inside the crown (the habit of gathering), and a viewpoint (a culmination).

\section{R7_Renata Radovanović: The Meat Factory}

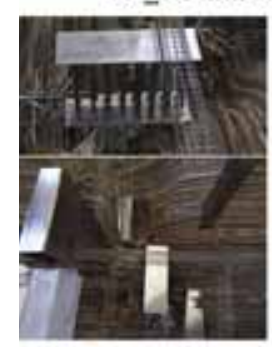

The Meat Factory is a provocation, a strategic game that asks oneself who he really is. It is physical structure for grinding human fascination with consumerism. By using the a natural canal, to create a space that draws us in and "won't let" us out, she creates a place with no clear entrance or exit. Nature is the foundation on which the network of choices constructed from the spatial contrasts is introduced, articulated in labyrinth pattern. Nature preserves its essence, while the role of architecture is to direct the man to play around with nature in a new and unexpected way.

R8_Marko Slavković: Forced Rehabilitation

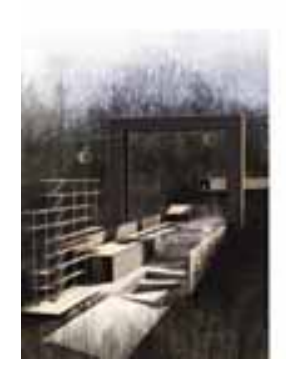

Forced Rehabilitation is a mechanism for active recovery from the city life. Conceptualized on the bases of Spa typology, the centre contains: the hall vacuum cleaner (a multitude of cloths hung from the ceiling through which the user navigates as through the forest), the strolling sauna (a continuous ramp passing from the lowest high heat and humidity area up to the cold showers), the rhythm pool (two lanes, one for fast swimming and the other with a jumping trampoline), the portal (a frame where hanging bags are placed overlooking the city), and the reading room (a hollow structure open on all sides).

Figure 6: Examples of the students' design projects.

\section{A DISCUSSION TOWARDS A NEW PARADIGM IN ARCHITECTURE}

The results vary from inspired associations to creative dialogues, from designs that complement to those that contrast the environment. Although the diverse concepts have produced a series of diametrically different solutions, they all are affirmative of the revitalisation of Košutnjak. Solutions may vary in terms of disposition, size, program and scope; however, they are united in terms of 
complementing the materiality and sensuality of the place by relating the designed structure to the natural environment.

It was not easy for the students to create architecture without any typology proposed. During research, they realised that both program and space primarily related to the character of the place and were dependent on its constant change.

Regarding the complexity of the relationship between concept and context, three approaches are clearly distinguished: (1) blending in with the natural environment (R1, R2, R3, R4), (2) emphasising the naturalness of the landscape (R6, R7) and (3) complementing the forest by introducing urban content and character (R5, R8; Figs 5 and 6).

The first approach (blending in with the natural environment or 'disappearing in nature') aims to create leisure places or intimate gardens - 'pieces' of nature characterised with minimal use of architectural elements. These interventions show that it is possible to use nature as a structural element of creation, emphasising an environmental approach to producing a new cultural landscape. The second approach highlights the landscape using it as a playground. It resolves the potential conflict between the urban and the natural by leaving enough space for man to shape the given environment through its active involvement. The focus of these interventions is on experiential components of nature. While the first approach is guided by natural and inherited values of the place, the second is influenced by the activity patterns that draw inspiration from nature. Finally, the third approach forces the context to become an incubator for urban life. Architecture here serves as a framework that should preserve vitality of naturalness at the same time reflecting contemporary urban lifestyle.

Looking at the complexity of the relationship between concept and content, a range of solutions can be easily distinguished, from those completely associative, in which the program is minimal and the space is limited by the view (Fig. 5: R1, R2, R3, R4), to those in which boundaries determine the variety of everyday activities (Fig. 6: R5, R6, R8). Although results vary from large to small scale, from the visible to the invisible, from the formal to the informal and ephemeral, they all offer a unique answer. Architectural design in protected natural and cultural-historical environment can contribute to sustainable development either through the introduction of various urban events, or through man's engagement in an action-reaction relationship with nature.

In terms of expressive design, three spatial concepts can be distinguished: (1) emphasising the footpath patterns in the forest (Figs 5 and 6: R4, R5, R7), drawing conceptual connection from the rhythm and articulation of the natural environment (walking and roaming); (2) highlighting the uniqueness of a particular site (Fig. 5: R1, R2, R3) with an obvious association to the character of the place; and (3) stressing the natural through introducing the urban (Fig. 6: R5, R6, R8). The first concept has the quality of an event, the second the quality of a sensation and the third one the quality of comfort.

Regarding materiality of architecture, all interventions include nature as their structural element (the earth as a cliff, embankment, foundation or cavity, the tree as a border or centre of gravity, or ephemeral material in the form of a sound, wind, light or seasonal foliage). None of the designs is notable for its appearance but rather for the spectrum of various events it offers, which is related to the degree of animation of natural scenery. In that way, the designs emphasise the importance of establishing a dialogue between the need for protecting and promoting nature and the respect for the standards entailed in the concept of sustainability.

Therefore, a new architectural paradigm includes sustainability as a resource so that nature is joined with architecture to make a unique place-based system in which the landscape is neither context nor background, but its structural component (Fig. 7). Nature's cyclic quality makes space flexible and adaptable while architecture offers a platform for including man in the quotidian life of nature. Recovering landscape is seen through the leisure content, at the same time urban and 


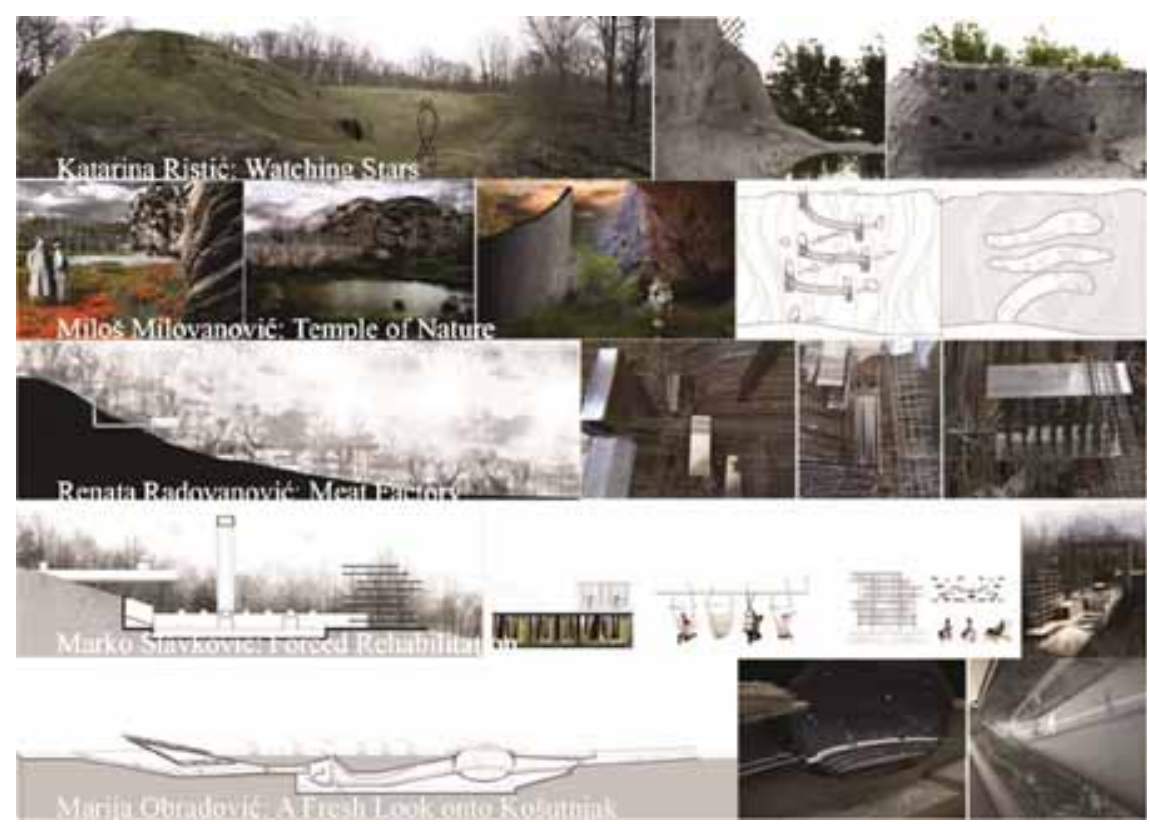

Figure 7: Diversity of students' designs.

contextually connected to landscape. Sustainability is achieved through the quality of revitalised nature in which architecture has become a method and nature an element that builds the structure. In addition, these structures may appeal to the younger population, to whom the encounter with nature has become unfamiliar and sometimes even slightly uncomfortable.

\section{CONCLUSIONS}

This article suggests three key areas that could lead to the new architectural paradigm establishing the relationship between architecture and nature: the roles of design elements, the power of learning from nature and the landscape revitalisation.

First, architecture becomes a tool for emphasising nature by turning design elements into elements of nature. Landscape is shaped through surreal materiality, where sound, smell, light and shade become the leading elements of architectural intervention. Under the influence of numerous conditions between the material and the sensual, the static logic of architecture undergoes transformation as to restructure its relationship to both man and context.

Second, the power of learning from nature affects the material and sensual understanding of architecture, broadening the range within which it is conceptualised. The pure definition of the program and the existing typologies has been challenged, offering an emotional experience that could become a generator for a cultural form.

Finally, landscape revitalisation is seen through a cultural dimension. In that respect, the two entities, nature and architecture, which are seemingly different, are linked in a unique spatial system: Landscape as a Living System: The Cultural Landscape.

The research helped to adopt a more comprehensive and sustainable approach to landscape. The selected design projects show students' ability to think about heritage in a holistic way and suggest key issues in the process of redefining historic and cultural layers on the one hand and spatial and 
semantic framework of the landscape on the other. We conclude that there is a need to conduct further professional studies in revitalising cultural-historical sites of natural beauty.

\section{ACKNOWLEDGEMENT}

This paper was realised as a part of the project 'Studying climate change and its influence on the environment: impacts, adaptation and mitigation' (43007) financed by the Ministry of Education and Science of the Republic of Serbia within the framework of integrated and interdisciplinary research for the period 2011-2014.

\section{REFERENCES}

[1] Nikezic, A. \& Jankovic, N., Košutnjak - Landscape as a Learning System. WIT Transactions on Ecology and the Environment, 160, eds. C.A. Brebbia \& S. Hernandez, WIT Press: Southampton, pp. 55-67, 2012.

[2] Benzel, F.K., The Room in Context. Design Beyond Boundaries, Princeton architectural press: New York, 1996.

[3] Van der Laan, D.H., Nature and architecture. Architectonic Space: Fifteen Lessons on the Disposition of the Human Habitat, Brill Academic Publishers: Leiden, pp. 1-11, 1983.

[4] Soria Lopez, F.J., Architecture and nature at the end of the 20th century: towards a dialogical approach for sustainable design in architecture. WIT Transactions on the Built Environment, 86, WIT Press: Southampton, pp. 23-33, 2006.

[5] Van Hal, A., The keyword is quality not ecology. Eco-Architecture: Harmonisation between architecture and nature. WIT Transactions on the Built Environment, 86, WIT Press: Southampton, pp. 35-44, 2006. doi: http://dx.doi.org/10.2495/ARC060041

[6] Anselm, A.J., Developing designs in balance with nature. Eco-Architecture: Harmonisation between architecture and nature. WIT Transactions on the Built Environment, 86, WIT Press: Southampton, pp. 195-205, 2006. doi: http://dx.doi.org/10.2495/ARC060201

[7] Pallasma, J., The Eyes of the Skin: Architecture and the Senses, 2nd edn., Wiley: New York, 1996. 